This item was submitted to Loughborough's Research Repository by the author.

Items in Figshare are protected by copyright, with all rights reserved, unless otherwise indicated.

\title{
Effects of grounding configurations on post-contingency performance of MTDC system: a 3-terminal example
}

PLEASE CITE THE PUBLISHED VERSION

http://dx.doi.org/10.1109/UPEC.2015.7339912

PUBLISHER

(C) IEEE

VERSION

AM (Accepted Manuscript)

\section{PUBLISHER STATEMENT}

This work is made available according to the conditions of the Creative Commons Attribution-NonCommercialNoDerivatives 4.0 International (CC BY-NC-ND 4.0) licence. Full details of this licence are available at: https://creativecommons.org/licenses/by-nc-nd/4.0/

\section{LICENCE}

CC BY-NC-ND 4.0

\section{REPOSITORY RECORD}

Gonzalez-Longatt, Francisco M., Jose L. Rueda, and M.A.M.M. Van Der Meijden. 2019. "Effects of Grounding Configurations on Post-contingency Performance of MTDC System: A 3-terminal Example". figshare. https://hdl.handle.net/2134/20521. 


\section{Effects of Grounding Configurations on Post- Contingency Performance of MTDC system: A 3-Terminal Example}

\author{
F. Gonzalez-Longatt \\ Loughborough University, UK \\ fglongatt@,fglongatt.org
}

\author{
J.L. Rueda \\ TU-Delft, Netherlands \\ j.1.ruedatorres@tudelft.nl
}

\author{
M.A.M.M. van der Meijden \\ TenneT TSO B. V, Netherlands \\ $\underline{\text { m.a.m.m.vandermeijden@tudelft.nl }}$
}

\begin{abstract}
The grounding system is extremely important, as it affects the performance of the MTDC system virtually in any possible mode: normal (asymmetrical operation) and abnormal operation (faults), steady-state and dynamic. The objective of this paper is to introduce a simple approach to assess the steadystate post-contingency of multi-Terminal HVDC System and uses it order to illustrate the effects of grounding configurations on steady-state post-contingency performance. A 3-terminal HVDC system is used to formulate the main theoretical framework for performance prediction on post-contingency steady-state of MTDC system as well as for demonstrative purposes.
\end{abstract}

Index Terms-- Asymmetrical operation, earthing, grounding, HVDC, post-disturbance, steady-state.

\section{INTRODUCTION}

European Union targets on reduction of $\mathrm{CO}_{2}$ emissions require a dramatic reduction in electricity generation sector making really important to maximize the power contribution coming from offshore wind power plants distant from the shore [1]. DC networks look quite attractive for the grid integration of this clean energy [2].

High Voltage DC (HVDC) transmission system based on Voltage Source Converter (VSC) enables the use of complex configuration as the multi-terminal use HVDC (MTDC) for the integration of large-scale wind power in the North Sea.

For several technical and safety reasons the MTDC installations must be grounded. The grounding systems in MTDC is essential for several reasons [3], [4]: to ensure the correct operation of electrical devices, to provide safety during normal or fault conditions, etc. The grounding system is extremely important, as it affects the performance of the MTDC system virtually in any possible mode: normal (asymmetrical operation) and abnormal operation (faults), steady-state and dynamic. Also, the grounding system defines susceptibility of the system to voltage transients, and helps to determine the system protection requirements.

Independently from the converter technology and topology, there are three main configurations for point-to-point HVDC transmission systems [5]: monopolar, homopolar and bipolar. For the relatively simple point-to-point HVDC connections a variety of configurations and earthling schemes has been reported in the literature [6].
MTDC systems are characterised when three or more converter stations become interconnected through the DC side of the transmission system. In the literature, various configurations and grounding types have been used to study MTDC or VSC-HVDC grids [5], [7].

The research in earthing and grounding configuration of MTDC is relatively new. The research team leads by D, Van Hertem has made contributions in this area in recent time [6, 7], however as other publications, [8,9] the core on those contributions is related to faults currents.

The objective of this paper is to establish the effects of grounding configurations on steady-state post-contingency performance of multi-Terminal HVDC System. Section II and III present the state-of-the-art on earthing and grounding configuration of point-to-point and MTDC systems. Section IV is dedicated to formulate the main theoretical framework of performance prediction on post-contingency steady-state of MTDC system, here effects of grounding configurations are illustrated and demonstrated using a 3-terminal HVDC system. Section IV presents numerical results of postcontingency steady-state operation, considering grounding configuration on a 3-terminal test system. DIgSILENT PowerFactory and MATLAB are used as simulation tools in this paper. Section $\mathrm{V}$ presents the main findings.

\section{POINT-TO-POINT HVDC LINKS}

This section present a review of the state-of-the-art on earthing and grounding configuration of point-to-point HVDC systems.

\section{A. Monopolar configuration}

The monopolar configuration is the simplest of all; two converters are connected by a single pole line and a positive or a negative DC voltage is used. This configuration conductor/cable/earth/sea return can be used. Negative polarity is mainly used in order to reduce corona effects. This configuration has one conductor and uses either grounded/or sea return [10].

Using ground as return path allows minimize the capital investment costs and transmission losses can be minimised (Fig 1.a). For instance, the Konti-Skan (1965) project (Sweden and Denmark) and Sardinia-Italy (mainland) (1967) project use monopolar links. However, in highly congested areas, or areas with high earth resistivity, or when fresh water 
crossing is involved, it may not be possible to use ground return. There are issues with corrosion of pipelines, production of chlorine and ship navigation. Whenever environmental issues, or interactions with metallic structures, constraint the use of ground return, a metallic return is used (Fig. 1.b). A metallic return can also be used where concerns for harmonic interference and/or corrosion exist. Finally, a symmetric monopole configuration (Fig. 1.c) can be utilised to avoid special transformers, however, in this case, two DC cables with full insulation are needed [5]. The symmetrical monopole configuration is unusual with line-commutated converters (LCC), however, the NorNed interconnection being an uncommon example, however, this configuration is very common with VSC when cables are used.

Most monopolar systems are designed for future bipolar expansion. Transmission line towers may be designed to carry two conductors, even if only one is used initially for the monopole transmission system. The second conductor is either unused, used as electrode line or connected in parallel with the other (e.g. Baltic-Cable [11] -Germany and Sweden).

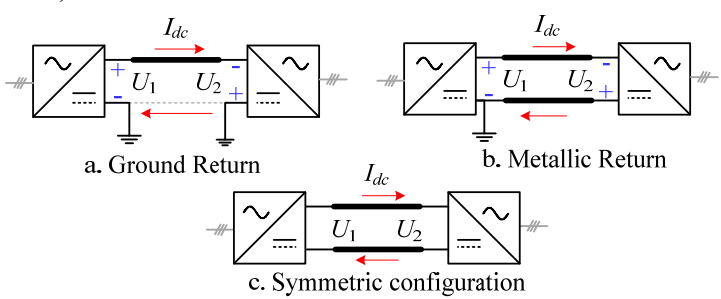

Fig. 1. Monopole configurations.

The symmetrical monopole configuration allows the use of fully rated HVDC cable as return conductor, then two VSC converters per pole can be utilised to double the power transferred using opposing voltage polarities.

\section{A. Homopolar configuration}

This configuration used two conductors having the same polarity (usually negative) can be operated with ground or metallic return [10]. Due to the undesirability of operating a DC link with ground return, bipolar links are mostly used. A homopolar link has the advantage of reduced insulation costs because two poles are operated in parallel, but the disadvantages of earth return outweigh the advantages [5].

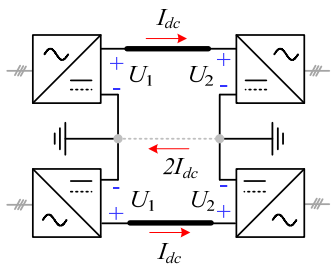

a. Ground Return

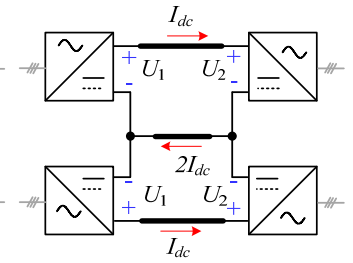

b. Metallic Return
Fig. 2. Homopolar configurations.

\section{B. Bipolar configuration}

This is the most commonly used configuration of HVDC transmission systems [12]. The bipolar configuration, uses two insulated conductors as positive and negative poles. The two poles can be operated independently if both neutrals are grounded. The bipolar configuration increases the power transfer capacity [5]. Under normal operation, the currents flowing in both poles are identical and there is no ground current. In case of failure of one pole power transmission can continue in the other pole which increases the reliability. Most overhead line HVDC transmission systems use the bipolar configuration. Monopolar operation can also be used in the first stages of the development of a bipolar link. Alternatively, under faulty converter conditions, one dc line may be temporarily used as a metallic return with the use of suitable switching [10].

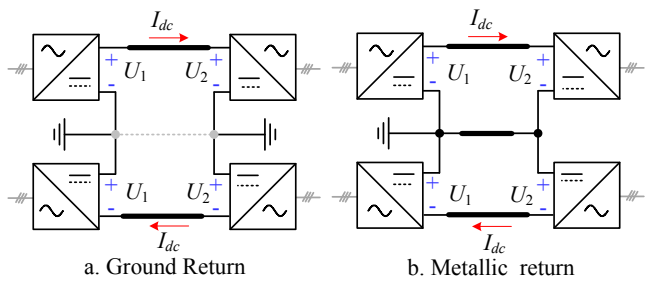

Fig. 3. Bipolar configurations.

\section{B. Back-to-Back (or B2B for short)}

This is the common configuration for connecting two adjacent asynchronous $\mathrm{AC}$ systems. Two converter stations are located at the same site and transmission line or cable is not needed. The DC voltage in the intermediate circuit $\left(U_{d c}\right)$ might be chosen freely at HVDC B2B stations because of the short conductor length.

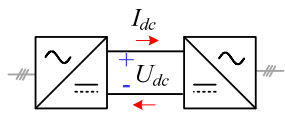

Fig. 4. Back-to-Back configuration.

In this paper, the B2B configuration is not considered for further analysis because is not revenant on discussion related to bulk power transmission.

\section{MTDC CONFIGURATIONS}

This section present a review of the state-of-the-art on earthing and grounding configuration of and MTDC systems.

MTDC system uses multiple infeed (three or more converter stations) in order to interconnect a DC transmission system. Converters substations can be interconnect on the following configurations (see Fig. 5): series, parallel, or hybrid (a mixture of series and parallel). Parallel configuration tends to be used for large capacity stations, and series for lower capacity stations.

MTDC using parallel connection allows all the converter terminals share the transmission system DC voltage $\left(U_{d c}\right)$. An example is the 2,000 MW Quebec-New England Transmission system. Systems based on parallel connections can be grouped into two categories (see Fig. 6): radial and meshed networks.

Development on MTDC is expected to increase in coming years. The world's first 3-terminal VSC-HVDC system is installed in China. The pilot project with designed ratings of $\pm 160 \mathrm{kV} / 200 \mathrm{MW}-100 \mathrm{MW}-50 \mathrm{MW}$ brings dispersed, 
intermittent clean wind power generated on Nanao Island into the mainland Guangdong power grid through $32 \mathrm{~km}$ of combination of HVDC land cables, sea cables and overheard lines. Then, on 4th July 2014, the $\pm 200 \mathrm{kV}$ Zhoushan VSCHVDC project, become the world first 5-terminal in service $(141 \mathrm{~km})$. That project establishes a critical interconnection between mainland and 5 isolated islands.

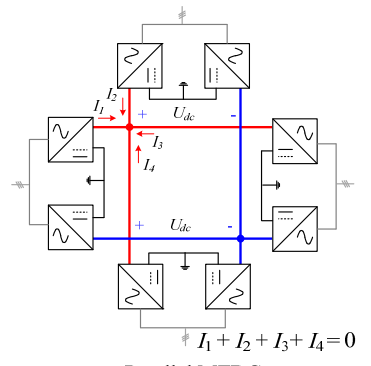

a. Parallel MTDC

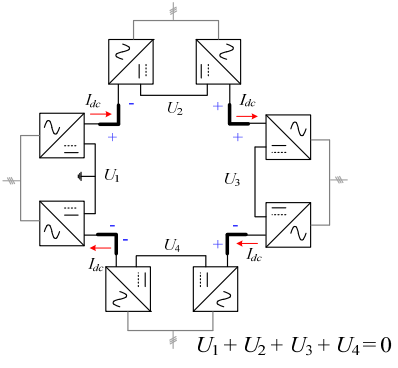

b. Series MTDC
Fig. 5. MTDC configuration: series or parallel.

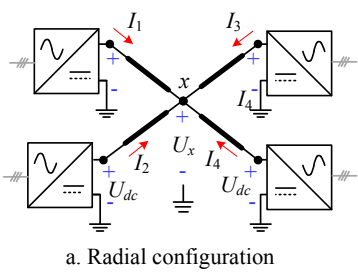

(a) Radial

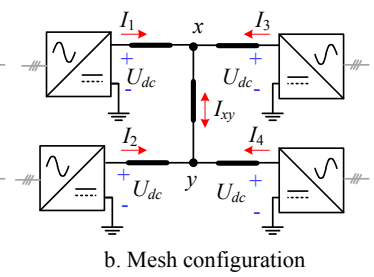

(b) Meshed
Fig. 6. MTDC parallel configuration: radial or meshed.

\section{StEAdy-STATE OF MTDC Systems}

This Section presents the mathematical background required on the steady-state analysis of a MTDC systems. A simple 3-terminal HVDC systems is used for illustrative purposes but the undergoing understanding explained here can be extended to larger configurations.

\section{A. System Configuration}

A simple MTDC test system is used in this paper for demonstratives purposes. It is a 3 -terminal, $\pm 200 \mathrm{kVdc}$, VSCHVDC (see Fig. 7). This is a representative network of the integration of offshore wind power coming from the North Sea. At first glance it looks like a very simplistic network, however, it has all main elements and components for illustrative purposes. Full details of the test system can be found in [13].

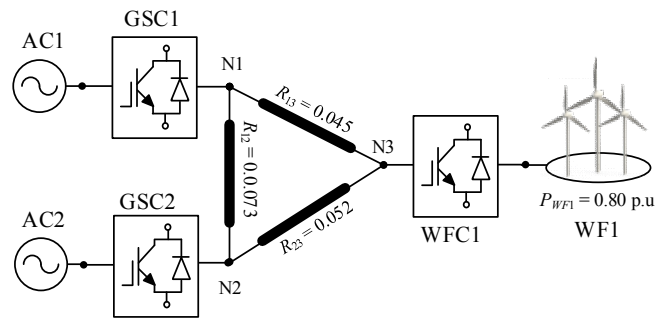

Fig. 7. Test system: Values of resistors $R_{i j}$ are shown in p.u [13].

B. Network Model

This section is presents the main mathematical background on the steady-state modelling of the MTDC system. DC cable between two nodes (e.g. $i$ and $j$ ) are represented using a single series resistor $R_{i j}$. DC side of converter stations are modelled by an ideal dependant voltage source and ideal ground is represented as an ideal point where voltages is zero. All electrical quantities are represented using per unit systems. The mathematic modelling of some grounding configuration of MTDC systems are presented here.

1) Monopole configuration: Ideal Ground Return

Let start with the most basic and simple configuration, monopolar configuration considering ideal earth return as presented on Fig. 8.

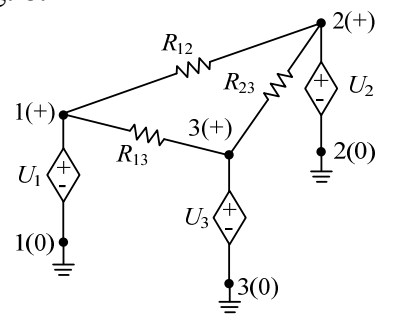

Fig. 8. Test system: Circuital representation of monopole ideal ground return.

The converter voltage $\left(U_{i}\right)$ can be expressed in terms of the terminal potentials:

$$
\begin{aligned}
& {\left[\begin{array}{l}
U_{1}^{(+)} \\
U_{2}^{(+)} \\
U_{3}^{(+)}
\end{array}\right]-\left[\begin{array}{l}
U_{1}^{(0)} \\
U_{2}^{(0)} \\
U_{3}^{(0)}
\end{array}\right]=\left[\begin{array}{l}
U_{1} \\
U_{2} \\
U_{3}
\end{array}\right]} \\
& \mathbf{U}^{(+)}-\mathbf{U}^{(0)}=\mathbf{U}
\end{aligned}
$$

$U_{i}^{(+)}$represents electrical potential of the transmission terminal and $U_{i}^{(0)}$ is used to define potential of the neutral terminal. For this specific case, monopolar configuration with ideal ground return, the voltage at the neutral point $(0)$ is connected to ideal ground where the electric potential is assumed zero, $\mathbf{U}^{(0)}=\mathbf{0}$, as consequence: $\mathbf{U}^{(0)}=\mathbf{U}$.

The current injected $\left(I_{i}\right)$ is written into a matrix form [14] using the conductance matrix $(\mathbf{G})$ of the DC grid can be used:

$$
\begin{aligned}
& {\left[\begin{array}{l}
I_{1} \\
I_{2} \\
I_{3}
\end{array}\right]=\left[\begin{array}{lll}
G_{11} & G_{12} & G_{13} \\
G_{21} & G_{22} & G_{23} \\
G_{31} & G_{32} & G_{33}
\end{array}\right]\left[\begin{array}{l}
U_{1}^{(+)} \\
U_{2}^{(+)} \\
U_{3}^{(+)}
\end{array}\right]} \\
& \mathbf{I}=\mathbf{G U}^{(+)} \quad \rightarrow \quad \mathbf{I}=\mathbf{G U}
\end{aligned}
$$

where the DC current vector $\mathbf{I}=\left[I_{1}, I_{2}, \ldots, I_{d c, n d c}\right]^{\mathrm{T}}, \quad \mathbf{U}=\left[U_{1}\right.$, $\left.U_{2}, \ldots, U_{n d c}\right]^{\mathrm{T}}$ is the DC voltage vector and $\mathbf{G}$ is also known as the DC nodal admittance matrix $\left(G_{i j}, i, j=1, \ldots n_{d c}\right)$.

The current injections I are not known prior to the power flow solution for the DC network. The vector $\mathbf{P}=\left[P_{1}, P_{2}\right.$, $\left.\ldots, P_{n d c}\right]^{\mathrm{T}}$, which refers to power flow into the DC grid via the $\mathrm{DC}$ terminals, is given by [15]:

$$
\mathbf{P}=\mathbf{U} \otimes(\mathbf{G U})
$$

where the symbol $\otimes$ is entry-wise (point-to-point) matrix multiplication operator. Equation (3) is known as the power balance equation and it can be solved in order to obtain the classical power flow solution of the MTDC system.

2) Monopole configuration: Real Ground Return Let consider a real ground return on a monopolar 
configuration, as shown on Fig. 9. In this configuration $R_{\text {gndi }}$ represents the neutral-grounding resistor and node $i$, it is connecting the neutral point $(0)$ and ideal ground. The converter voltage $\left(U_{i}\right)$ can be expressed in terms of the terminal potentials as presented in (1).

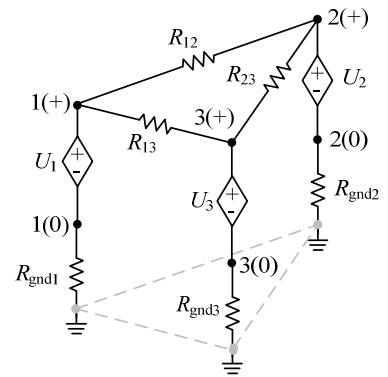

Fig. 9. Test system: Circuital representation of monopole with real ground return $\left(R_{\text {gndi }}\right)$.

The potential of the neutral points (0) are calculated based on the grounding resistors $\left(R_{\text {gndi }}\right)$ :

$$
\begin{aligned}
& {\left[\begin{array}{l}
U_{1}^{(0)} \\
U_{2}^{(0)} \\
U_{3}^{(0)}
\end{array}\right]=} {\left[\begin{array}{ccc}
R_{\text {gnd } 1} & 0 & 0 \\
0 & R_{\text {gnd } 2} & 0 \\
0 & 0 & R_{\text {gnd } 3}
\end{array}\right]\left[\begin{array}{c}
I_{1} \\
I_{2} \\
I_{3}
\end{array}\right] } \\
& \mathbf{U}^{(0)}=\mathbf{R}_{\text {gnd }} \mathbf{I}
\end{aligned}
$$

Combining (1) and (4)

$$
\begin{gathered}
{\left[\begin{array}{c}
U_{1}^{(+)} \\
U_{2}^{(+)} \\
U_{3}^{(+)}
\end{array}\right]=\left[\begin{array}{l}
U_{1} \\
U_{2} \\
U_{3}
\end{array}\right]+\left[\begin{array}{ccc}
R_{\text {gnd } 1} & 0 & 0 \\
0 & R_{\text {gnd } 2} & 0 \\
0 & 0 & R_{\text {gnd } 3}
\end{array}\right]\left[\begin{array}{c}
I_{1} \\
I_{2} \\
I_{3}
\end{array}\right]} \\
\mathbf{U}^{(+)}=\mathbf{U}+\mathbf{R}_{\text {gnd }} \mathbf{I} \\
\mathbf{I}=\left[\mathbf{R}_{\text {gnd }}\right]^{-1} \mathbf{U}^{(+)}-\left[\mathbf{R}_{\text {gnd }}\right]^{-1} \mathbf{U}
\end{gathered}
$$

The conductance matrix $(\mathbf{G})$ as on (2)

$$
\mathbf{I}=\mathbf{G} \mathbf{U}^{(+)} \quad \rightarrow \quad \mathbf{U}^{(+)}=\mathbf{G}^{-1} \mathbf{I}
$$

Now, the combining (5) and (6):

$$
\begin{gathered}
\mathbf{I}=\left[\mathbf{R}_{\text {gnd }}\right]^{-1} \mathbf{G}^{-1} \mathbf{I}-\left[\mathbf{R}_{\text {gnd }}\right]^{-1} \mathbf{U} \\
{\left[\text { ones }-\left[\mathbf{R}_{\text {gnd }}\right]^{-1} \mathbf{G}^{-1}\right] \mathbf{I}=-\left[\mathbf{R}_{\text {gnd }}\right]^{-1} \mathbf{U}} \\
\mathbf{I}=-\left[\text { ones }-\left[\mathbf{R}_{\text {gnd }}\right]^{-1} \mathbf{G}^{-1}\right]^{-1}\left[\mathbf{R}_{\text {gnd }}\right]^{-1} \mathbf{U}
\end{gathered}
$$

Finally the power balance equations for this configuration is described by:

$$
\mathbf{P}=\mathbf{U} \otimes\left\{-\left[\text { ones }-\left[\mathbf{R}_{\text {gnd }}\right]^{-1} \mathbf{G}^{-1}\right]^{-1}\left[\mathbf{R}_{\text {gnd }}\right]^{-1} \mathbf{U}\right\}
$$

where ones represents the identity matrix or unit matrix. It is simple to demonstrate (3) is a very specific case of (8) where $R_{\text {gndi }}=0$.

3) Other Configurations

The power balance equations of other grounding configuration (as shown Fig 10 and 11) are created using the same mathematical procedure presented before. They are not presented here for space constraints.

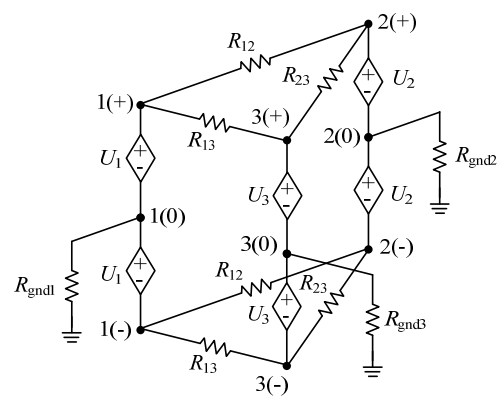

Fig. 10. Test system: Circuital representation: Bipolar ground return.

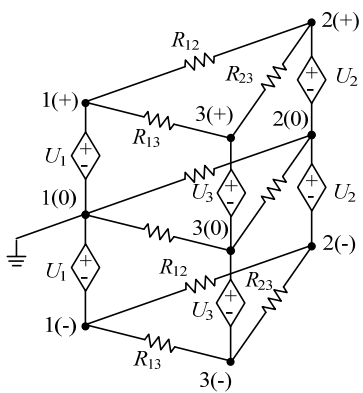

Fig. 11. Test system: Circuital representation: Bipolar Metallic return.

\section{Optimization Problem Formulation}

The steady-state performance of a MTDC system is described by the power flow, it is be described by a set of nonlinear algebraic equations:

$$
\mathbf{G}(\mathbf{X}, \mathbf{Y}, \mathbf{Z})=\mathbf{0}
$$

where $\mathbf{G}$ is the set of algebraic equations define the powerbalance at network nodes as shown in previous Sections, and $\mathbf{X}$ is state vector and $\mathbf{Y}$ is the vector of independent variable and $\mathbf{Z}$ is a vector of control variables. In this paper, postcontingency steady-state is calculated transforming the nonlinear algebraic mathematical problem and transforming it into an optimization problem. The reason from this transformation underlays on taking advantage of representing the specific behaviour of HVDC system using constraints.

Bound constraints: VSC converters are used to control DC voltage inside MTDC. Those power converters, usually use IGBTs as commutation devices which are extremely sensible and have very low capacity to cope with voltages changes. DC overvoltage which may stress the commutation devices and extremely low under-voltages can cause destructive overcurrent on the IGBT. As consequence there are limits with regard to steady state voltage ranges at the converter stations. In this paper, the limits on the voltage of the $i$-th VSC converter $\left(U_{i}\right)$ is written as bound constraints based on operational limits:

$$
U_{\min }<U_{i}<U_{\max }
$$

where $U_{\min }$ and $U_{\max }$ represent the minimum and maximum allowed voltage. The use of bound constraints allow met technical operational limits but at the same time, there is a mathematical advantages because allow to obtain faster and more reliable solutions because the searching space is 
reduced.

Nonlinear equality constraints: Inside a MTDC network, $\mathrm{DC}$ control is certainly one of the most important tasks given to converter stations. There several DC voltage control modes used on a VSC-HVDC terminal. In this paper DC voltage droop control is used, it tries to control power to its reference level while at the same time contributing some balancing power. DC voltage droop characteristic is shown in Fig. 12.

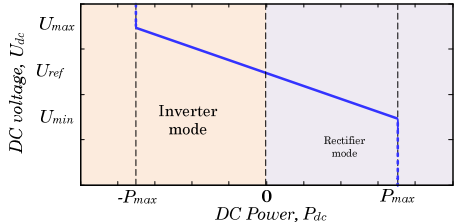

Fig. 12. $D C$ voltage versus power characteristic of $D C$ voltage controller.

The DC voltage droop constant $\left(\rho_{D C}\right)$ and the DC voltage response $\left(R_{D C}\right)$ are related to each other by:

$$
\frac{P_{\text {rated }}}{U_{\text {rated }} \rho_{D C}}=R_{D C}
$$

where $P_{\text {rated }}$ and $U_{\text {rated }}$ refer to rated power and rated DC voltage of the DC terminal, respectively. The relation between DC voltage $\left(U_{d c}\right)$ and converter power $\left(P_{d c}\right)$ at steady on a VSC-HVDC terminal using DC voltage droop control is given by:

$$
U_{d c}=U_{r e f}+\frac{1}{R_{D C}}\left(P_{r e f}-P_{d c}\right)
$$

Linear inequalities: There is a very strict current limitation on VSC converter used in MTDC systems. The power converter commutation devices, usually IGBTs, have very little, if any, overcurrent capacity. The VSC control system will make sure that the converter valves maximum current is not exceeded:

$$
\mathbf{I}_{\text {conv }}<\mathbf{I}_{\text {conv }}^{\max }
$$

where $\mathbf{I}_{\text {conv }}^{\text {max }}$ represents a vector containing the maximum loading current allow in each converter station. Using the nodal analysis, the nodal current can be transformed into a set of linear inequalities constraints as follow:

$$
\mathbf{I}_{\text {conv }}=\mathbf{Y}_{\mathrm{dc}} \mathbf{U}_{\mathrm{dc}}<\mathbf{I}_{\text {conv }}^{\text {max }}
$$

\section{Simulation And Results}

A MTDC system, consisting of two AC grids and one wind farm shown in Fig. 7, is used for illustrative purposes. Two different DC voltage control modes are used on the VSC-HVDC terminals: constant power control mode on the wind farm converter station $\left(P_{3}\right)$ and DC voltage droop control on the grid side converter stations $\left(U_{1}\right.$ and $U_{2}, \rho_{D C 1}=$ 0.0005 and $\rho_{D C 2}=0.0002 \mathrm{p} . \mathrm{u} / \mathrm{MW}$ ), thus enabling $\mathrm{N}-1$ security. All simulations are performed using a PC based on Intel $^{\circledR}$, Core $^{\mathrm{TM}}$ i7-7410HQ CPU $2.5 \mathrm{GHz}, 16 \mathrm{~GB}$ RAM with Windows 8.1 64-bit operating system.

\section{System Modelling Testing}

The modelling and solution approach presented on Section IV is initially tested for demonstrative purposes. A MATLAB ${ }^{\circledR}$ R2014a (64-bit) program (m-file) has been developed for this very specific propose. Interior-point algorithm is used to solve the optimization problem in this paper. Bound constraints are considered in all simulations in order to ensure a secure system operation $\left(0.90<U_{d c}<1.10\right.$ p.u). Linear inequalities is not included in this testing because this is a very operational condition not provided in commercial software.

Numerical results of $N-1$ contingency analysis in DIgSILENT PowerFactory v15.2.4 are used for comparative purposes. Bipolar earth return configuration of Test System shown in Fig. 7 is used for testing purposes $\left(R_{g n d 1}=1 \Omega, R_{\text {gnd } 2}\right.$ $=2 \Omega, R_{\text {gnd } 3}=3 \Omega$ ). Monopolar configuration is not considered here for space limitations. Simulations results of steady-state operation over the Test System are shown on Fig. 13 and comparison with the approach presented in Section IV are presented on Table I.

In this paper, the contingency used for illustrative purposes is a simple DC cable outage. This contingency is the simplest and easiest to include in the mathematical procedure described in Section IV. The contingency is modelled affecting the correspondent element in the conductance matrix (G).

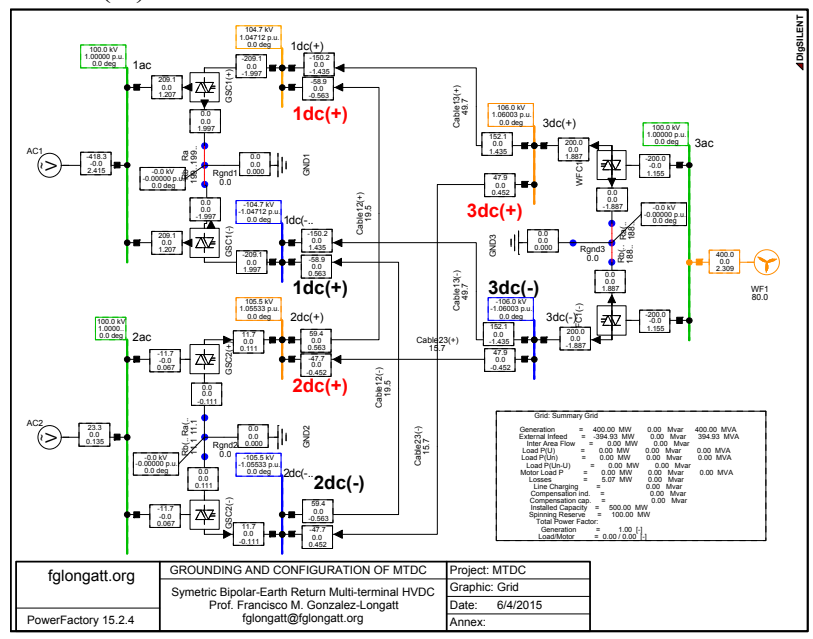

Fig. 13. Test system: Bipolar Earth Return Configuration. Numerical results obtained using DIgSILENT PowerFactory.

TABLE I

Simulation Results of $N$-1 CONTINGENCY ANALysis: CABles Outage. BIPOLAR EARTH RETURN CONFIGURATION

\begin{tabular}{c|c|c|c}
\hline \hline Node & $\begin{array}{c}\text { Voltage (p.u) } \\
\text { DIgSILENT }\end{array}$ & $\begin{array}{c}\text { Voltage (p.u) } \\
\text { MATLAB }\end{array}$ & Contingency \\
\hline $3 \mathrm{dc}(-)$ & -1.0791 & -1.0791 & Cable13(-) \\
$2 \mathrm{dc}(-)$ & -1.0600 & -1.0598 & Cable13(-) \\
$1 \mathrm{dc}(-)$ & -1.0510 & -1.0508 & Cable23(-) \\
$3 \mathrm{dc}(+)$ & 1.0791 & 1.0791 & Cable13(+) \\
$2 \mathrm{dc}(+)$ & 1.0600 & 1.0598 & Cable13(+) \\
$1 \mathrm{dc}(+)$ & 1.0510 & 1.0508 & Cable23(+) \\
\hline
\end{tabular}

DC cable outage is an important contingency because create an important change on the power flows (magnitudes and directions) in the DC-transmission system and postcontingency is interesting from the grounding point of view. Comparison results demonstrate a minimal numerical 
discrepancies between the DIgSILENT PowerFactory and proposed method. The largest numerical difference in postcontingency states is below $\pm 0.002 \mathrm{p}$.u, as consequence, the proposed method can be used with minor discrepancies.

\section{A. Grounding Assessment}

This section presents an illustrative comparison between grounding schemes uses in the bipolar configuration. Let consider three specific cases: Case I: bipolar ideal earth return $\left(R_{\text {gnd }}=0\right)$, Case II, bipolar earth return $\left(R_{\text {gnd } 1}=1 \Omega\right.$, $R_{\text {gnd } 2}=2 \Omega, R_{\text {gnd } 3}=3 \Omega$ ), Case III: bipolar (no ground return). Those cases allow a post-contingency comparison between configuration considering values of grounding resistors. Numerical simulation results of post-contingency state are presented on Table II. Simulations are based on simple contingency, DC cable outage. It is not a surprise how the use of low grounding resistor (Case I, ideal return) provided the lowest post contingency DC voltages. As happen in $\mathrm{AC}$ system, including higher values of grounding resistor increases the DC voltages after the contingency. It should be noticed the use of bipolar configuration without any grounding connection provides the highest post-contingency DC voltages. It must recognised the benefits of using earth path return in asymmetrical DC systems. There are two major positive impacts: it helps to control post-contingency dc voltages and also provided alternative current path helping on the power flow distribution on weakly connected DC terminals.

TABLE II

RESULTS COMPARISON OF $N$-1 CONTINGENCY ANALYSIS: GROUNDING

\begin{tabular}{c|c|c|c|c}
\hline \hline Node & Case I & Case II & Case III & Contingency \\
\hline $3 \mathrm{dc}(-)$ & -1.0783 & -1.0791 & -1.0884 & Cable13(-) \\
$2 \mathrm{dc}(-)$ & -1.0590 & -1.0598 & -1.0706 & Cable13(-) \\
$1 \mathrm{dc}(-)$ & -1.0512 & -1.0508 & -1.0595 & Cable23(-) \\
$3 \mathrm{dc}(+)$ & 1.0783 & 1.0791 & 1.0884 & Cable13(+) \\
$2 \mathrm{dc}(+)$ & 1.0590 & 1.0598 & 1.0706 & Cable13(+) \\
$1 \mathrm{dc}(+)$ & 1.0512 & 1.0508 & 1.0595 & Cable23(+) \\
\hline
\end{tabular}

VI. CONCLUSIONS

As in $\mathrm{AC}$, system the grounding system in DC systems is extremely important. Grounding configurations of multiterminal HVDC systems using bi-polar converter are the most interesting off all configurations because it might help to support post-contingency DC voltage. Selection of final grounding scheme and grounding resistors require a complete DC system analysis. Grounding configuration affects the performance of the MTDC system virtually in any possible mode: normal (asymmetrical operation) and abnormal operation (faults), steady-state and dynamic. This paper has two contribution (i) to introduce a simple optimization-basedapproach to calculate the steady-state post-contingency of MTDC systems and (ii) to use that approach in order to illustrate basic effects of grounding configurations on steadystate post-contingency performance. A 3-terminal HVDC system is used to formulate the main theoretical framework for performance prediction on post-contingency steady-state of MTDC system as well as for demonstrative purposes.
However, the system model presented here can be extended for larger configurations. Simulation results demonstrates the use of the proposed modelling and solution approach and present a brief discussion about the effect grounding configuration in a bi-polar configuration on the postcontingency state.

\section{ACKNOWLEDGEMENTS}

This work was supported in part by British Council under the UKIERI, under grant DST/INT/UK/P-61/2014.

\section{REFERENCES}

[1] F. Gonzalez-Longatt, "Optimal steady-state operation of a MTDC system based on DC-Independent System Operator Multi-objective," presented at the The 11th International Conference on $\mathrm{AC}$ and $\mathrm{DC}$ Power Transmission, ACDC 2015, Birmingham, United Kingdom, 2015

[2] F. Gonzalez-Longatt, "Optimal Power Flow of a MTDC system considering DC-Independent System Objective " International Transactions on Electrical Energy Systems, IN REVIEW.

[3] P. De Oliveira-De Jesus, A. Rojas Q, and F. Gonzalez-Longatt, "Unbalanced Power Flow Analysis in Distribution Systems Using TRX Matrix: Implementation Using DIgSILENT Programming Language," in PowerFactory Applications for Power System Analysis, F. M. Gonzalez-Longatt and J. Luis Rueda, Eds., ed: Springer International Publishing, 2014, pp. 85-110.

[4] J. M. Roldan-Fernandez, F. Gonzalez-Longatt, J. Rueda, and H. Verdejo, "Modelling of Transmission Systems Under Unsymmetrical Conditions and Contingency Analysis Using DIgSILENT PowerFactory," in PowerFactory Applications for Power System Analysis, F. M. Gonzalez-Longatt and J. Luis Rueda, Eds., ed: Springer International Publishing, 2014, pp. 27-59.

[5] R. Texeira, "Multi-Terminal DC Networks: System Integration, Dynamic and Control," PhD Thesis, Department of Electrical Sustainable Energy, Technische Universiteit Delft, 2014.

[6] S. De Boeck, P. Tielens, W. Leterme, and D. Van Hertem, "Configurations and earthing of HVDC grids," in Power and Energy Society General Meeting (PES), 2013 IEEE, 2013, pp. 1-5.

[7] W. Leterme, P. Tielens, S. De Boeck, and D. Van Hertem, "Overview of Grounding and Configuration Options for Meshed HVDC Grids," Power Delivery, IEEE Transactions on, vol. PP, pp. 1-1, 2014.

[8] E. Berne, G. Bergna, P. Egrot, and Q. Wolff, "Earth currents in HVDC grids: An example based on 5 terminal bipolar configurations," in Power Electronics and Applications (EPE'14-ECCE Europe), 2014 16th European Conference on, 2014, pp. 1-10.

[9] M. K. Bucher and C. M. Franck, "Comparison of fault currents in multiterminal HVDC grids with different grounding schemes," in PES General Meeting | Conference \& Exposition, 2014 IEEE, 2014, pp. 1-5.

[10] V. K. Sood, HVDC and FACTS controllers : applications of static converters in power systems. Boston: Kluwer Academic Publishers, 2004.

[11] AB. Baltic Cable AB. Available: http://www.balticcable.com/

[12] K. R. Padiyar, HVDC power transmission systems : technology and system interactions. New York: Wiley, 1990.

[13] F. Gonzalez-Longatt. (2015). Multi-Terminal HVDC Systems: 3 Node $+1 W F+2 A C \quad$ Test System Available: http://www.fglongatt.org/Test Systems/3-Node+1WF+2AC.html

[14] F. Gonzalez-Longatt, J. M. Roldan, and C. A. Charalambous, "Solution of ac/dc power flow on a multiterminal HVDC system: Illustrative case supergrid phase I," in 47th International Universities Power Engineering Conference (UPEC 2012), 2012, pp. 1-7.

[15] T. M. Haileselassie and K. Uhlen, "Impact of DC Line Voltage Drops on Power Flow of MTDC Using Droop Control," Power Systems, IEEE Transactions on, vol. 27, pp. 1441-1449, 2012. 